\title{
Technology Development to Measure Vertical Height and High Aspect Ratio Using Chromatic Confocal
}

\author{
Yeon Taek $\mathrm{OH}$ \\ Department of Mechanical Engineering, Tongmyong University \\ 428 Sinseon-ro, Nam-gu, Busan, Korea \\ yeonoh@tu.ac.kr
}

\begin{abstract}
Electronic parts are becoming small and thin parts are very precise and refined accordingly, requiring measurement of part shapes. In particular, parts structures that have high aspect ratio and dozens of millimeters high vertical resolution need to be measured in the 3D measurement area. To measure 3D shape of high vertical resolution, the study suggested measuring technology with synchronization of stage and chromatic confocal. It also suggested the chromatic confocal with high NA value to measure high aspect ratio structures with high slope and technology to measure the sample by inclining and fixing this. The suggestion would make real time $3 \mathrm{D}$ shape measurement possible of the sample with high vertical resolution and high aspect ratio without surface treatment. Convergence of measurement probe would also enable shape measurement of nano-size structure surface in various fields.
\end{abstract}

Keyword - Aspect ratio, Chromatic confocal, Multi probe, Stage, High vertical resolution, 3D shape

\section{INTRODUCTION}

Measurement is needed to verify parts in industrial area. Electronic goods are becoming small and their parts are very precise and refined accordingly. As the parts also rapidly become highly precise and large in the display industry, they call for shape measurement.

Optical measurement, or two-dimensional geometric measurement, uses a microscope and CCD camera. However, 3D shape measurement technology is emerging to measure the micro shape in the semiconductor and display industry. Since the micro shape has very large aspect ratio, thus requiring high spatial resolution to observe 3D shape, scanning electron microscope or scanning probe microscope is used. This method measures a very small area after surface treatment of the sample and has its limit to measure without changing the form of the sample. Therefore, industries use confocal and white light microscope that can measure it without sample deformation.

Besides, the optical measurement technology we have now has its limit to observe the shape height of the high aspect ratio. With increasing sales of IT goods in particular, there is also increasing need to measure structures having high aspect ratio and parts requiring scope of about $20 \mathrm{~mm}$ vertical resolution. Composite measurement of the increasingly precise and large mold to manufacture the parts is also on the rise (1). Combining with sensors submicron non-contact probes, a multi-purpose device that can measure highly precise shapes and structures with high aspect ratio in the 3D measurement area, the study developed high-speed/high-precision multi probe measurement system that has precise shape measurement function in the same location for 3D large area measuring scope. However, measuring shape of high aspect ratio has its limit (2). The study discussed the technology that is able to measure longitudinal and high aspect ratio of structures to overcome such limit.

\section{Extending longitudinal measurement scope}

Longitudinal measurement scope of the chromatic confocal developed in the high-speed/high-precision multi probe measurement system ( $Z$ axis measurement scope) was $1.1 \mathrm{~mm}$ (2). To extend the longitudinal measurement scope of the chromatic confocal to $20 \mathrm{~mm}$, the chromatic confocal was installed at the $z$ stage as Fig 1 showed, the $\mathrm{z}$ stage and the chromatic confocal were synchronized, z-stage was moved to maintain a regular interval with the sample, which were tracked to measure its height. 


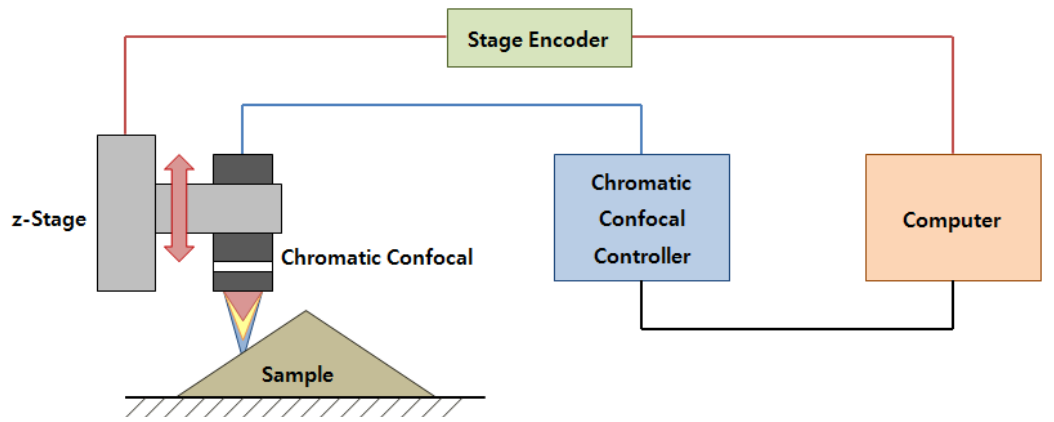

Fig. 1. Diagram of longitudinal measurement scope

The chromatic confocal used as a measuring sensor to keep a regular interval with the sample was designed to record height with movement of z-stage and stage encoder when the interval between the two changed. The longitudinal measurement scope of the sample was decided by stroke of z-stage while the vertical resolution was decided by sum of resolution of z-stage and resolution of the chromatic confocal. Therefore, z-stage adopted a stage that had good resolution and accuracy with more than stroke $20 \mathrm{~mm}$. Fig 2 showed the chromatic confocal installed for $\mathrm{z}$-stage and Table 1 showed the z-stage specification applied to the system.

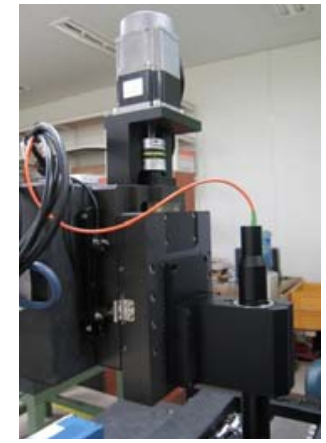

Fig. 2. chromatic confocal installed for z-stage

Table 1. Z-stage specification

\begin{tabular}{|c|c|}
\hline Item & specification \\
\hline Travel Range & $50 \mathrm{~mm}$ \\
\hline Resolution & $0.04 \mu \mathrm{m}$ \\
\hline Accuracy & $1 \mu \mathrm{m}$ \\
\hline Uni-Repeatability & $\pm 0.5 \mu \mathrm{m}$ \\
\hline Bi-Repeatability & $\pm 0.5 \mu \mathrm{m}$ \\
\hline Load Capacity & $20 \mathrm{~kg}$ \\
\hline
\end{tabular}

The longitudinal direction of the sample was measured to verify the built system like Fig 3 . The sample was manufactured with height at $20.11 \mathrm{~mm}$ after processing and surface polishing was done. The measurement using z-stage and chromatic confocal indicated $22.112 \mathrm{~mm}$ as Fig 3 showed. Synchronization of z-stage and chromatic confocal can increase the longitudinal measurement scope of the sample.

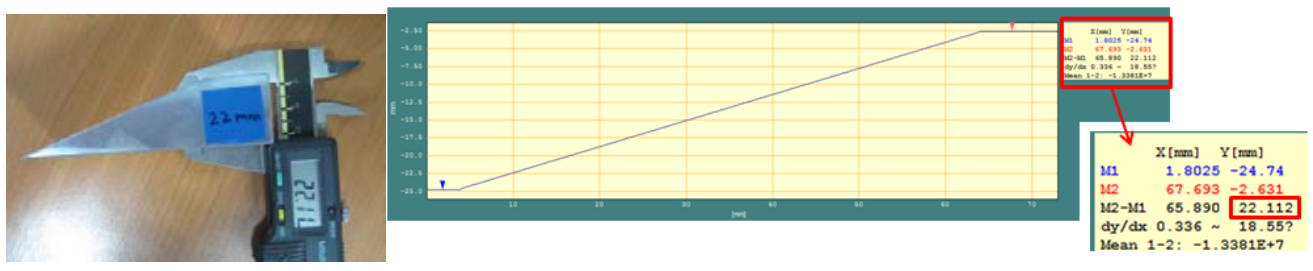

Fig. 3. Test sample and measurement result 


\section{Technology of High Aspect Ratio Measurement}

The maximum tilting angle of the sample that can be measured with the chromatic confocal was determined by NA of the chromatic confocal as Fig 4 presented. In general, NA of the chromatic confocal is 0.5 and the maximum measurable angle here is $\pm 30^{\circ}$. This means that NA has to be 0.985 to measure any sample with high aspect ratio of $80^{\circ}$. It is difficult and costly to manufacture lens with NA of 0.985 . The study measured the high aspect ratio by inclining the existing chromatic confocal and measured the angle that has high aspect ratio by correcting the inclined angle for the measure data.

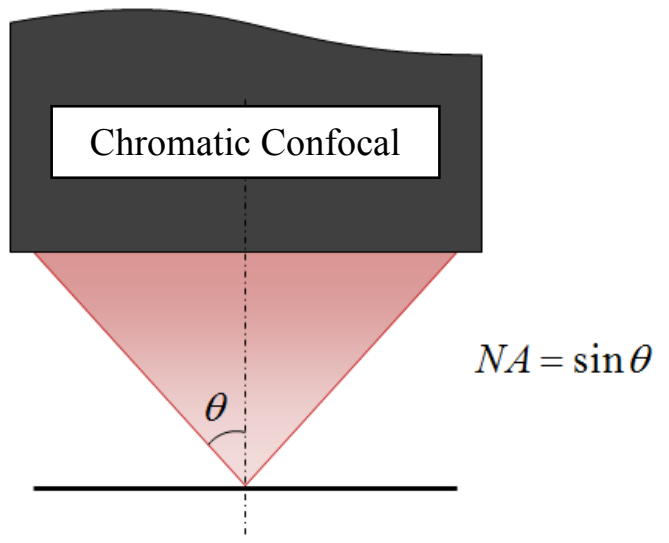

Fig. 4. Chromatic Confocal

As Fig 5 explained, NA could be reduced as much as the inclined angle of the chromatic confocal. Under the condition that NA of the chromatic confocal was $\theta_{\mathrm{NA}}$, the inclined angle was $\theta \mathrm{c}$ and the sample angle to be measured was $\theta$ s like Fig 5, measured data could be obtained, satisfying $\theta_{\mathrm{S}}<\theta_{\mathrm{NA}}+\theta_{\mathrm{C}}<90^{\circ}$.

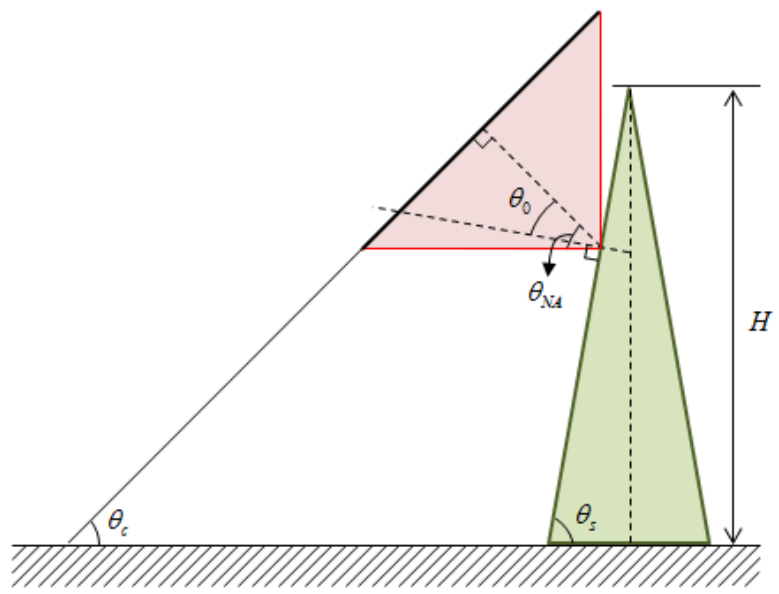

$$
\theta_{0}=\theta_{s}-\theta_{c} \quad \theta_{s}<\theta_{N A}+\theta_{c}<90^{\circ}
$$

$\theta_{N A}<\theta_{0} \quad$ Not possible to measurement

$\theta_{u=}=\theta_{0} \quad$ Theoretically possible measurement

but practically no possible due to low reflected light.

$\theta_{N A}>\theta_{0} \quad$ Possible to measurement

Fig. 5. Theory of high aspect ratio sample measurement

Design of the chromatic confocal should consider quantity of reflected light, sample inclined angle $\left(\theta_{\mathrm{S}}\right)$, sample pattern height $(\mathrm{H})$ and sample pattern interval $\left(\mathrm{W}_{\mathrm{PP}}\right)$. Quantity of reflected light is the light projected to a spectrometer (reflexibility) compared with the amount of light projected to the sample. When the reflexibility is low, light reflected from the spectrometer is low and vice versa. Besides, higher sample should generate great chromatic aberration occurrence scope of the chromatic confocal and the sample height should be determined by the optical system design as the chromatic aberration occurrence scope is limited. When the sample pattern is dense, the sample pattern interval is decided by the designed optical system as interference occurs with the optical path. The study considered all these to design the optical system of the chromatic confocal. 


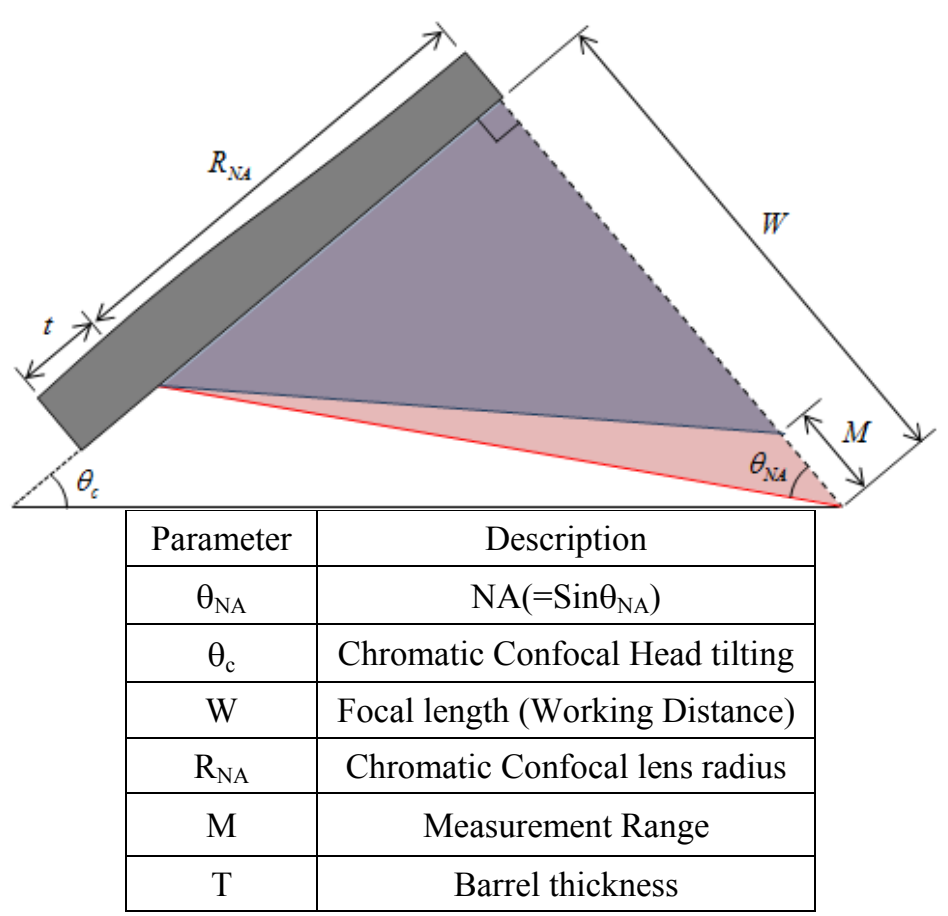

Fig. 6. Design parameter for the chromatic confocal

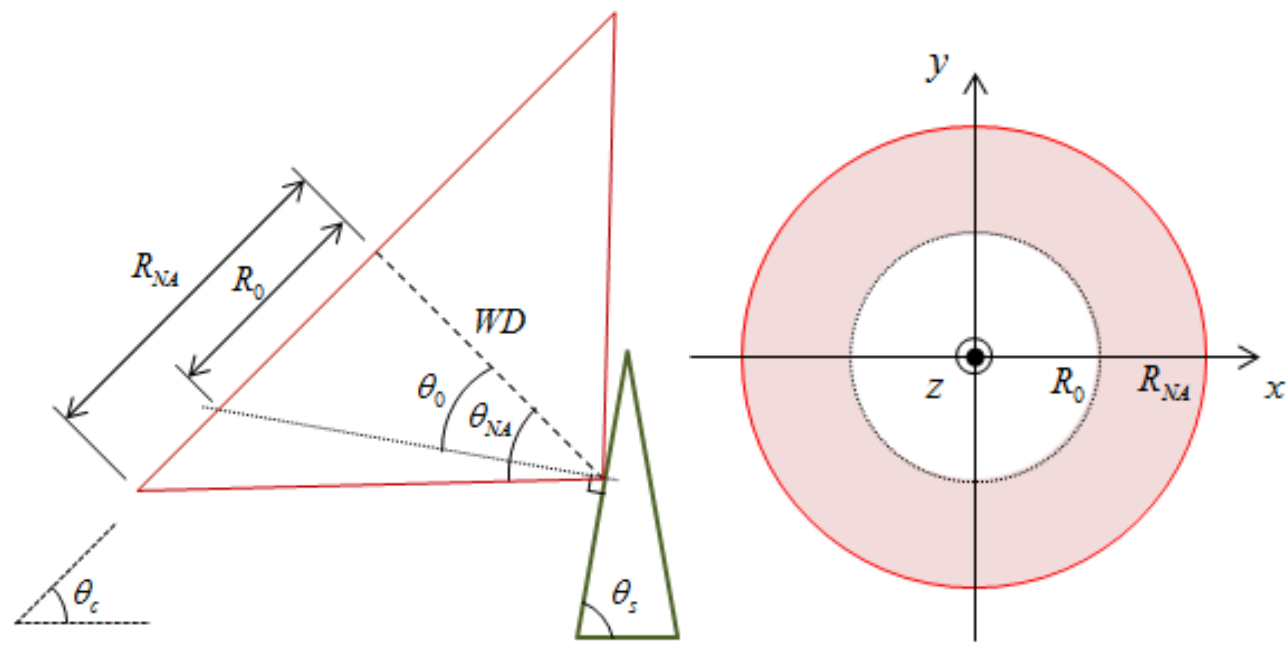

Fig. 7 Calculating reflexibility

The reflexibility of Fig 7 is as follows:

$$
\begin{gathered}
\left.\mathrm{p}_{\mathrm{t}} \text { (total light }\right)=\pi\left(\mathrm{R}_{\mathrm{NA}}\right)^{2} \\
\mathrm{p}_{\mathrm{r}}(\text { light refleted from the sample })=\pi\left(\mathrm{R}_{\mathrm{NA}}\right)^{2}-\pi\left(\mathrm{R}_{0}\right)^{2} \\
\frac{\mathrm{p}_{\mathrm{r}}}{\mathrm{p}_{\mathrm{t}}}=\frac{\pi\left(\mathrm{R}_{\mathrm{NA}}\right)^{2}-\pi\left(\mathrm{R}_{0}\right)^{2}}{\pi\left(\mathrm{R}_{\mathrm{NA}}\right)^{2}}=1-\frac{\tan ^{2}\left(\theta_{\mathrm{s}}-\theta_{\mathrm{c}}\right)}{\tan ^{2} \theta_{\mathrm{NA}}} \\
\text { Refl }=1-\frac{\tan ^{2}\left(\theta_{\mathrm{s}}-\theta_{\mathrm{c}}\right)}{\tan ^{2} \theta_{\mathrm{NA}}}
\end{gathered}
$$

The reflexibility is determined by the sample tilting $\left(\theta_{\mathrm{S}}\right)$, chromatic confocal tilting $\left(\theta_{\mathrm{C}}\right)$ and chromatic confocal NA $\left(\theta_{\mathrm{NA}}\right)$. Besides, as the chromatic confocal applies raster scan to measure and high sample may conflict with the chromatic confocal during measurement, measurable sample height can be calculated. The chromatic aberration occurrence scope can be calculated with the sample height. 


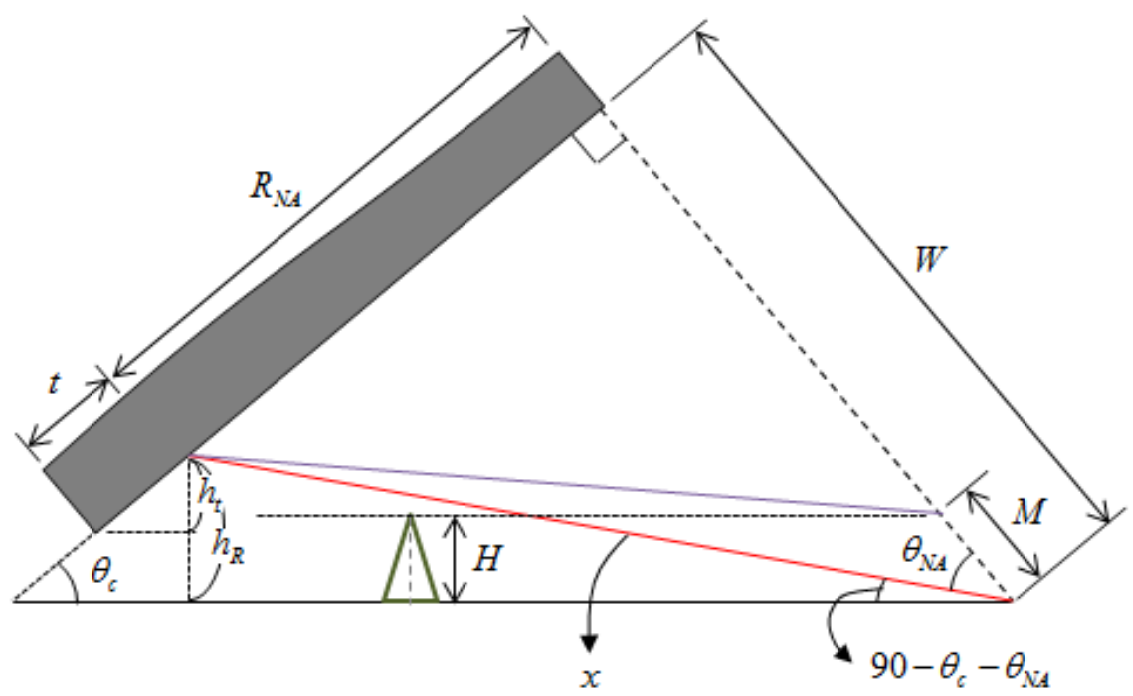

Fig. 8. Sample height calculation

$$
\begin{gathered}
\mathrm{h}_{\mathrm{t}}=\mathrm{t} \sin \theta_{\mathrm{c}} \\
\mathrm{x}=\frac{\mathrm{R}_{\mathrm{NA}}}{\sin \theta_{\mathrm{NA}}}=\frac{\mathrm{W}}{\cos \theta_{\mathrm{NA}}} \\
\mathrm{h}_{\mathrm{R}}=\mathrm{x} \sin \left(90-\theta_{\mathrm{c}}-\theta_{\mathrm{NA}}\right)=\mathrm{x} \cos \left(\theta_{\mathrm{c}}+\theta_{\mathrm{NA}}\right)=\frac{\mathrm{R}_{\mathrm{NA}} \cos \left(\theta_{\mathrm{c}}+\theta_{\mathrm{NA}}\right)}{\sin \theta_{\mathrm{NA}}}=\frac{\mathrm{W} \cos \left(\theta_{\mathrm{c}}+\theta_{\mathrm{NA}}\right)}{\cos \theta_{\mathrm{NA}}} \\
\mathrm{h}_{\mathrm{R}}-\mathrm{h}_{\mathrm{l}}=\mathrm{x} \sin \left(90-\theta_{\mathrm{c}}-\theta_{\mathrm{NA}}\right)-\mathrm{t} \sin \theta_{\mathrm{c}}=\frac{\mathrm{W} \cos \left(\theta_{\mathrm{c}}+\theta_{\mathrm{NA}}\right)}{\cos \theta_{\mathrm{NA}}}-\mathrm{t} \sin \theta_{\mathrm{c}} \\
\mathrm{H} \leq \frac{\mathrm{W} \cos \left(\theta_{\mathrm{c}}+\theta_{\mathrm{NA}}\right)}{\cos \theta_{\mathrm{NA}}}-\mathrm{t} \sin \theta_{\mathrm{c}} \\
\mathrm{M} \geq \frac{\frac{\mathrm{W} \cos \left(\theta_{\mathrm{c}}+\theta_{\mathrm{NA}}\right)}{\cos \theta_{\mathrm{NA}}}-\mathrm{t} \sin \theta_{\mathrm{c}}}{\cos \theta_{\mathrm{c}}}=\mathrm{W}-\mathrm{W} \tan \theta_{\mathrm{c}} \tan \theta_{\mathrm{NA}}-\tan \theta_{\mathrm{c}} \\
\mathrm{M} \geq \mathrm{W}-\mathrm{W} \tan \theta_{\mathrm{c}} \tan \theta_{\mathrm{NA}}-\tan \theta_{\mathrm{c}}
\end{gathered}
$$

Besides, the sample pattern interval can cause interference with the optical path of the chromatic confocal and lead to inaccurate data. Therefore, the pattern interval is also a critical factor to take into account.

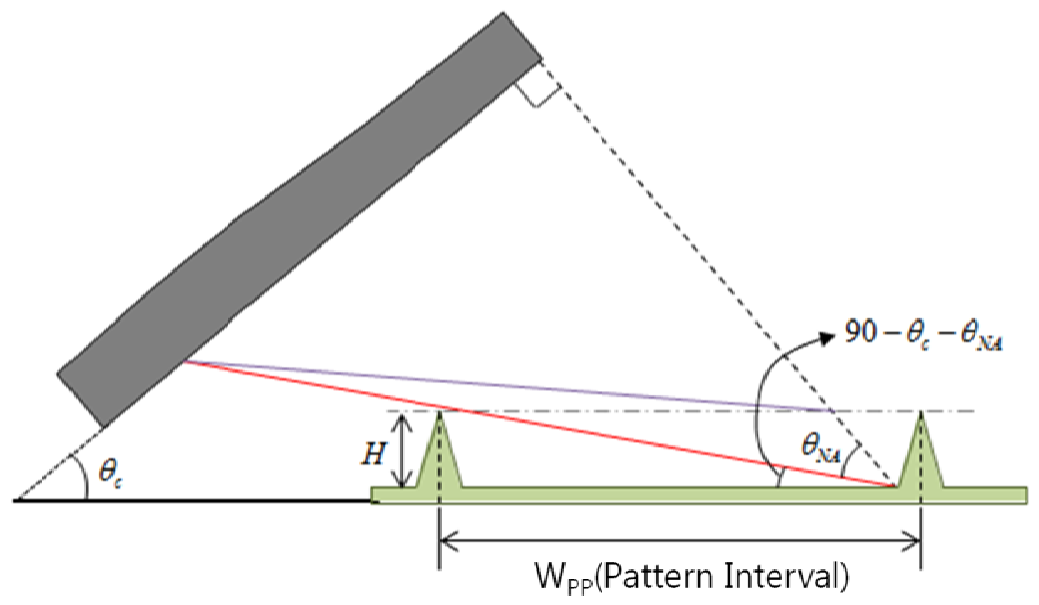

Fig. 9. Sample pattern interval calculation

$$
\begin{gathered}
\mathrm{W}_{\mathrm{pp}}=\frac{\mathrm{H}}{\tan \left(90-\theta_{\mathrm{c}}-\theta_{\mathrm{NA}}\right)} \\
\mathrm{W}_{\mathrm{pp}}=\frac{\mathrm{H}}{\cot \left(\theta_{\mathrm{c}}+\theta_{\mathrm{NA}}\right)}=\mathrm{H} \tan \left(\theta_{\mathrm{c}}+\theta_{\mathrm{NA}}\right)
\end{gathered}
$$


That is, when the sample pattern interval is smaller than the above result, interference occurs with the optical path of the chromatic confocal, causing inaccurate data. Thus, the pattern interval should be bigger than $\mathrm{W}_{\mathrm{pp}}$.

To sum up the consideration and parameters to design the chromatic confocal with high aspect ratio, measuring it is easier when the reflexibility and sample height is high and the pattern interval (W) does not affect the reflexibility. However, engineering limit should be considered although wider pattern interval (W) increases the chromatic aberration occurrence scope $(\mathrm{M})$. Based on the theory above, MATLAB was used to design the chromatic confocal, which has the following specification. Fig 10 showed the MALTLAB simulation on the measurable sample based on the design.

Table 2. Chromatic confocal specification

\begin{tabular}{|c|c|}
\hline Item & Specification \\
\hline Used wave & $486 \sim 656 \mathrm{~nm}$ \\
\hline Fiber diameter & $50 \mu \mathrm{m}$ \\
\hline Spot size & $2.5 \mu \mathrm{m}$ \\
\hline Magnification & $20 \mathrm{x}$ \\
\hline NA & 0.4 \\
\hline Working Distance & $32.5 \mathrm{~mm}$ \\
\hline
\end{tabular}

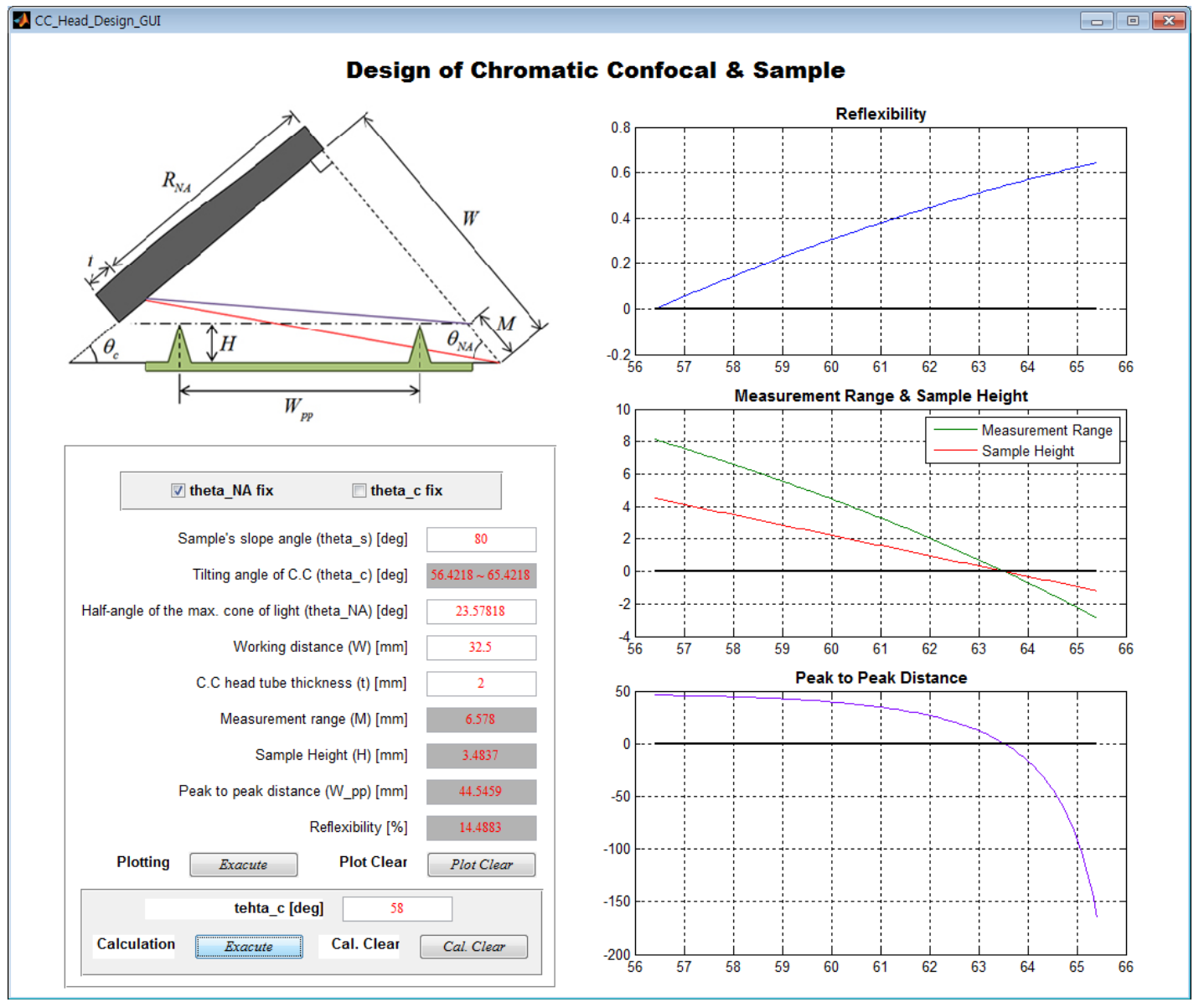

Fig. 10. Design of chromatic confocal optical part

Since NA was $0.4, \theta_{\mathrm{NA}}$ was about $23.578^{\circ}$. The simulation explained that the tilting angle range of the chromatic confocal was $56.4^{\circ} \sim 65.4^{\circ}$ with reflexibility at max. $62 \%$, measurable sample height at max. $4.5 \mathrm{~mm}$ and chromatic aberration range at $8 \mathrm{~mm}$. Reflexibility and sample height was inversely proportionate and this was determined by the tilting angle of the chromatic confocal. Therefore, the tilting angle should be $58^{\circ}$ or greater. When the angle was $58^{\circ}$, the maximum measurable sample height was $3.48 \mathrm{~mm}$ and the confocal aberration occurrence range was $6.58 \mathrm{~mm}$. However, actual specification was $1.81 \mathrm{~mm}$ and the measurable sample height 
was $959.2 \mu \mathrm{m}$ because the optical system could not be designed. The chromatic confocal was manufactured based on this. In consideration of little reflected light and loss in the optical fiber, two types were manufactured like Fig 12. One applied the beam splitter to make optical fiber for light incidence and optical fiber for detecting reflected light different so that loss in the optical fiber could be reduced even when the sample reflexibility was low. The other, meanwhile, was designed to use one optical fiber for light incidence and light reflection with the optical circulator.

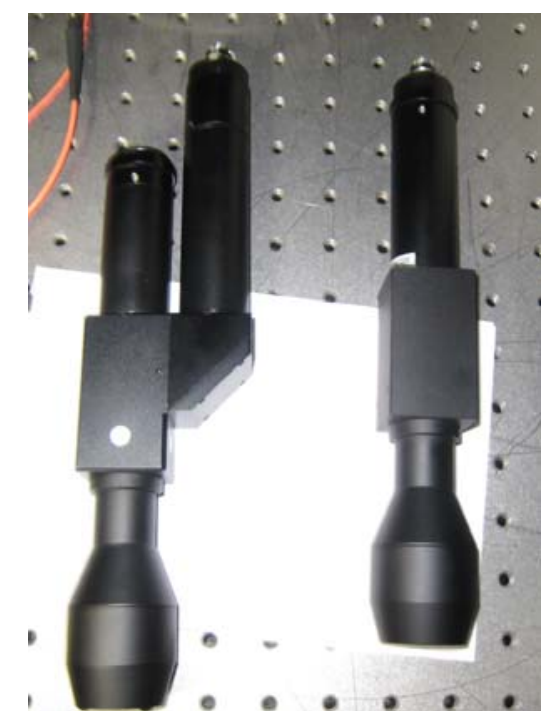

Fig. 11. Manufactured chromatic confocal(BS type, Straight type)

\section{Verification of Chromatic Confocal for High Aspect Ratio}

A. Calibration of chromatic confocal

The study calibrated the manufactured chromatic confocal. After installing the chromatic confocal for high aspect ratio vertically on a flat plate, the study measured line CCD pixel location by moving $200 \mu \mathrm{m}$ step z stage. It analyzed the data measured and found out optical resolution and measurement range. Fig 12 displayed the measured data.
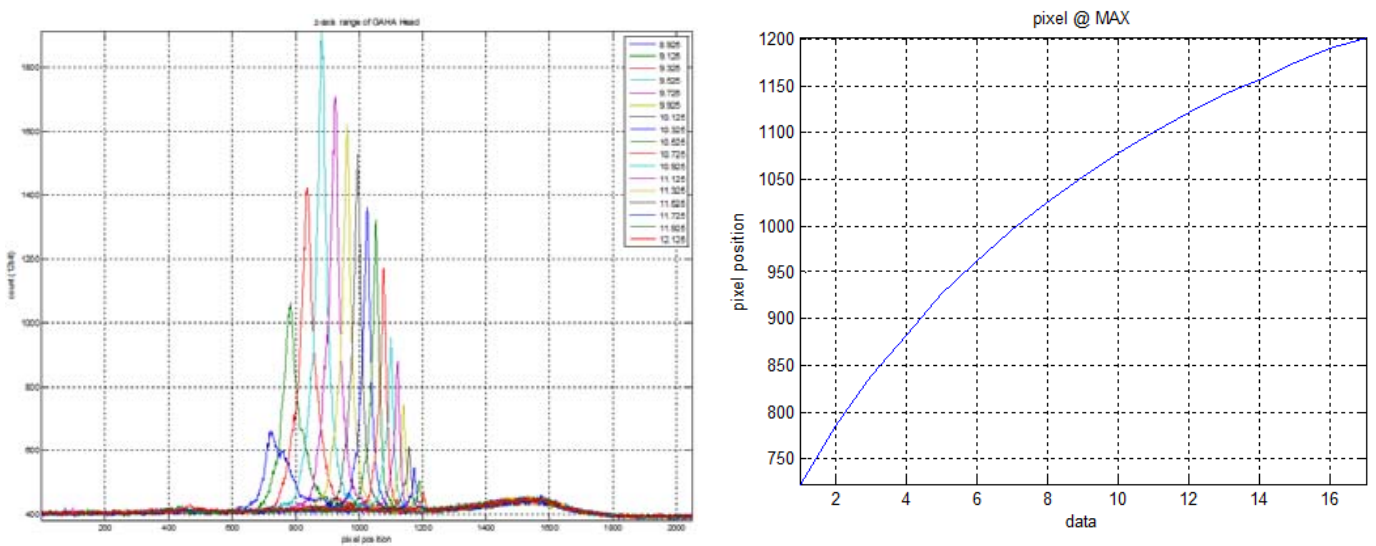

Fig. 12. Calibration measurement data of the chromatic confocal for high aspect ratio

It was found from the calibration that pixel position was nonlinear though the height was $200 \mu \mathrm{m}$ and changed linearly. Therefore, the scale value to convert the pixel position to height data was materialized not as a constant but as a function having the pixel position as a parameter. Based on the measurement, the scale function went through data fitting like the following $3 \mathrm{D}$ function and was corrected as below.

$$
\mathrm{H}=2 \times 10^{-8} \times \mathrm{p}^{3}-4 \times 10^{-8} \times \mathrm{p}^{2}+0.0359 \mathrm{P}-10.948
$$

B. Sample measurement with the chromatic confocal

H: height, P: pixel.

Reference sample was measured with the chromatic confocal for high aspect ratio to compare the measured value and sample value and the measuring performance of the chromatic confocal was compared. Fig 14 showed the measurement method using multi chromatic confocal. 


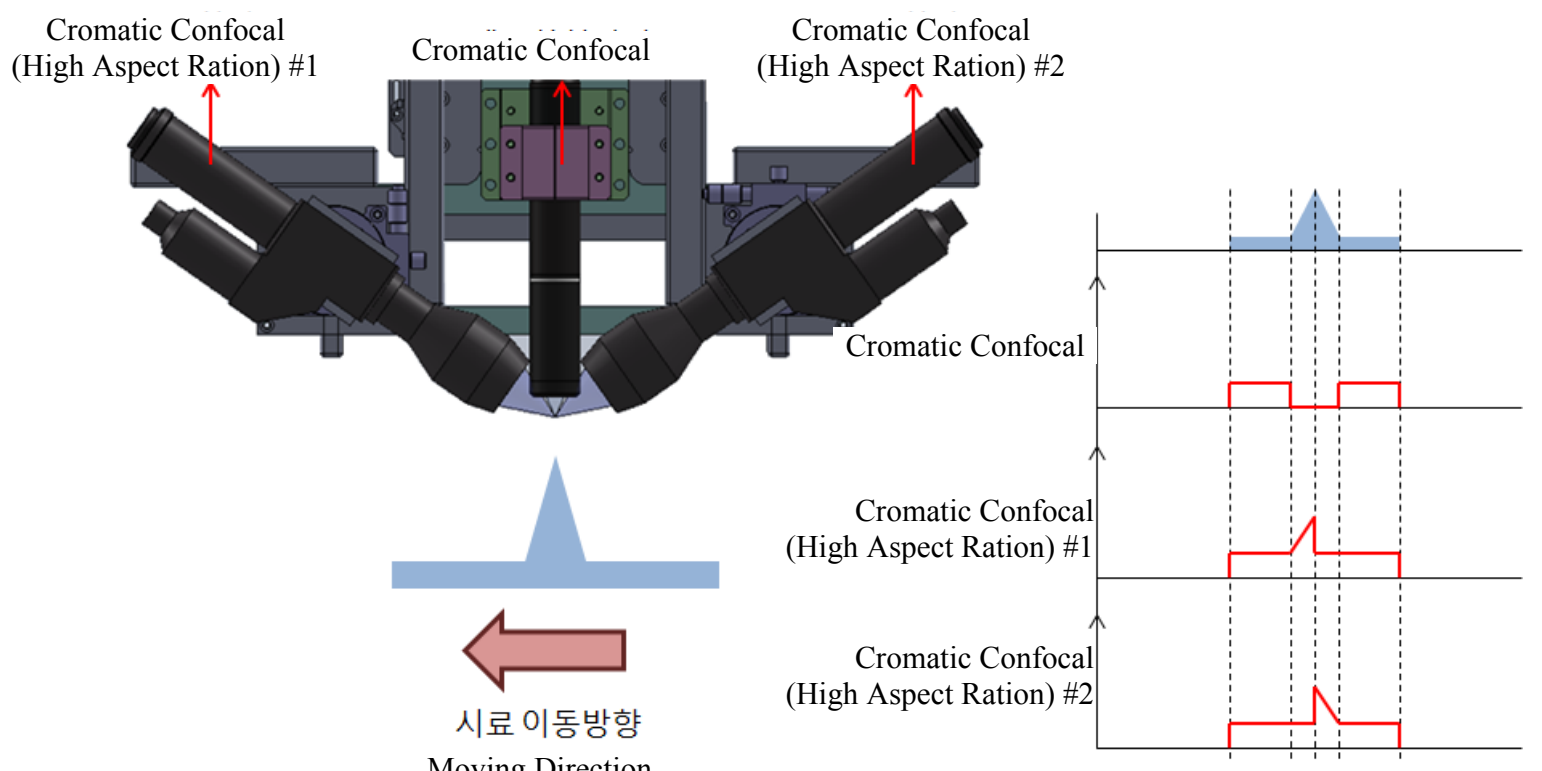

Moving Direction

Fig. 13. Sample measurement for high aspect ratio

The existing chromatic confocal could not measure the sample with large inclined angle or indicated inaccurate data. However, the chromatic confocal for high aspect ratio measured the height data for large inclined angle and corrected line CCD calibration, its tilting and measured data. Fig 14 presented how to correct sample height data with the chromatic confocal for high aspect ratio.

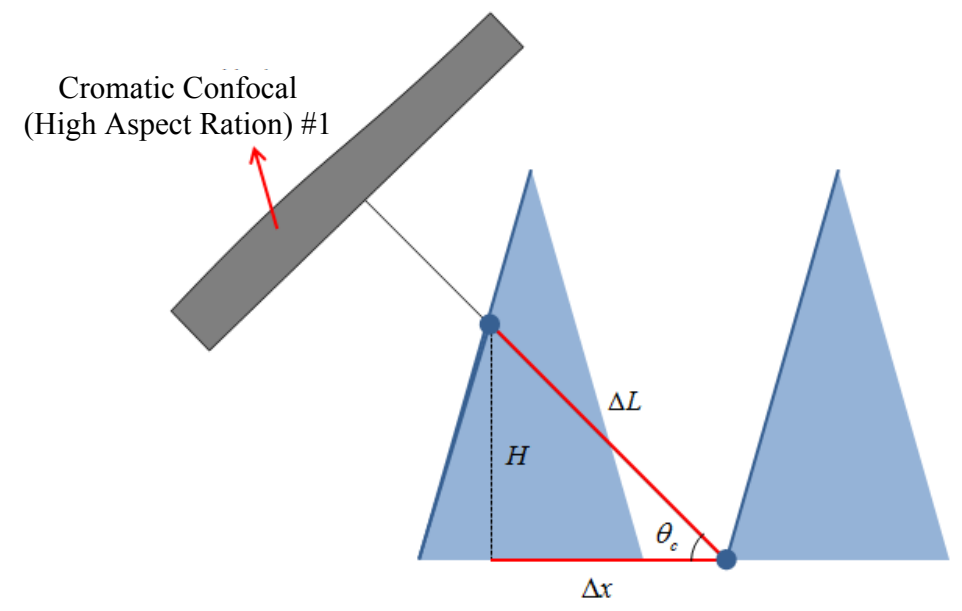

Fig. 14. How to correct sample height data for high aspect ratio

The data coming from the chromatic confocal for high aspect ratio were $\Delta \mathrm{L}$ and $\Delta \mathrm{x}$ while $\theta_{\mathrm{C}}$ was tilting angle. That is, $\Delta \mathrm{L}$ measured at each step (longitudinal resolution, $\Delta \mathrm{x}$ ) multiplying with $\operatorname{Sin} \theta_{\mathrm{C}}$ can produce the high aspect ratio sample height data. To measure the produced high aspect ratio sample, the sample was fixed to the plate and moved longitudinally as Fig 15 described. 

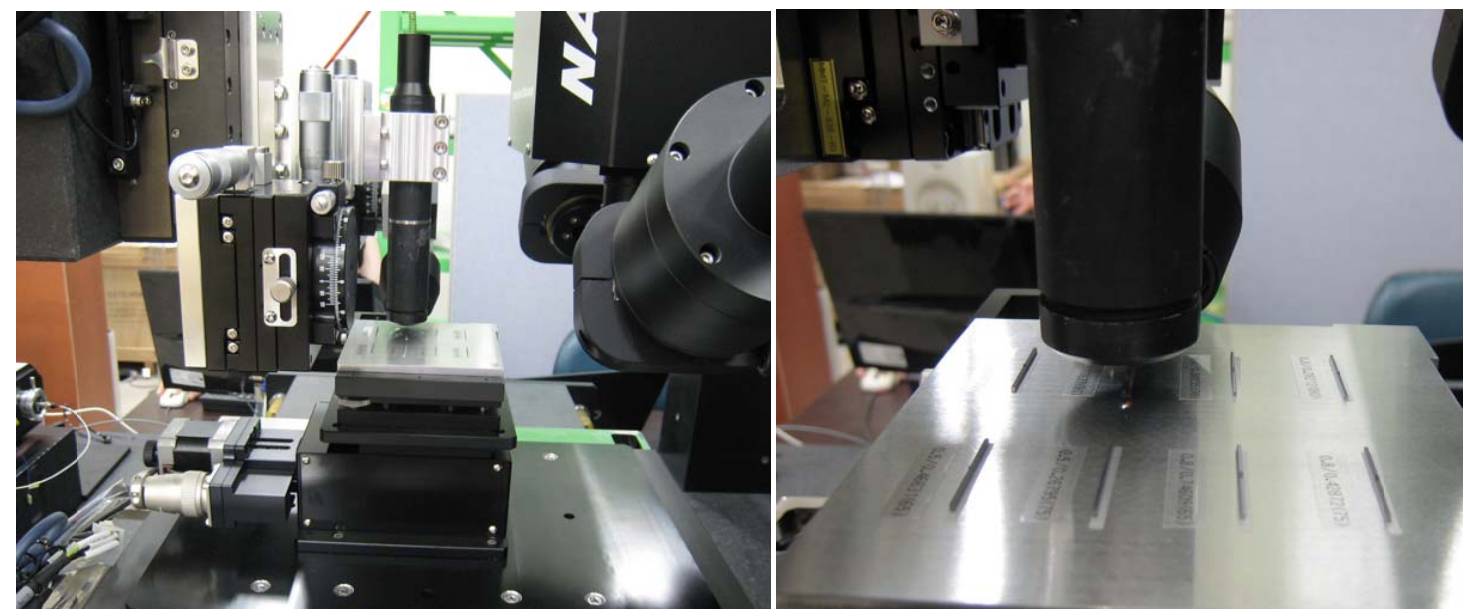

Fig. 15. High aspect ratio sample measurement

The existing chromatic confocal and designed chromatic confocal for high aspect ratio were measured the sample shape.

The sample with height of $800 \mu \mathrm{m}$ and inclined angle of $80^{\circ}$ was measured with the chromatic confocal and the profile was as below.

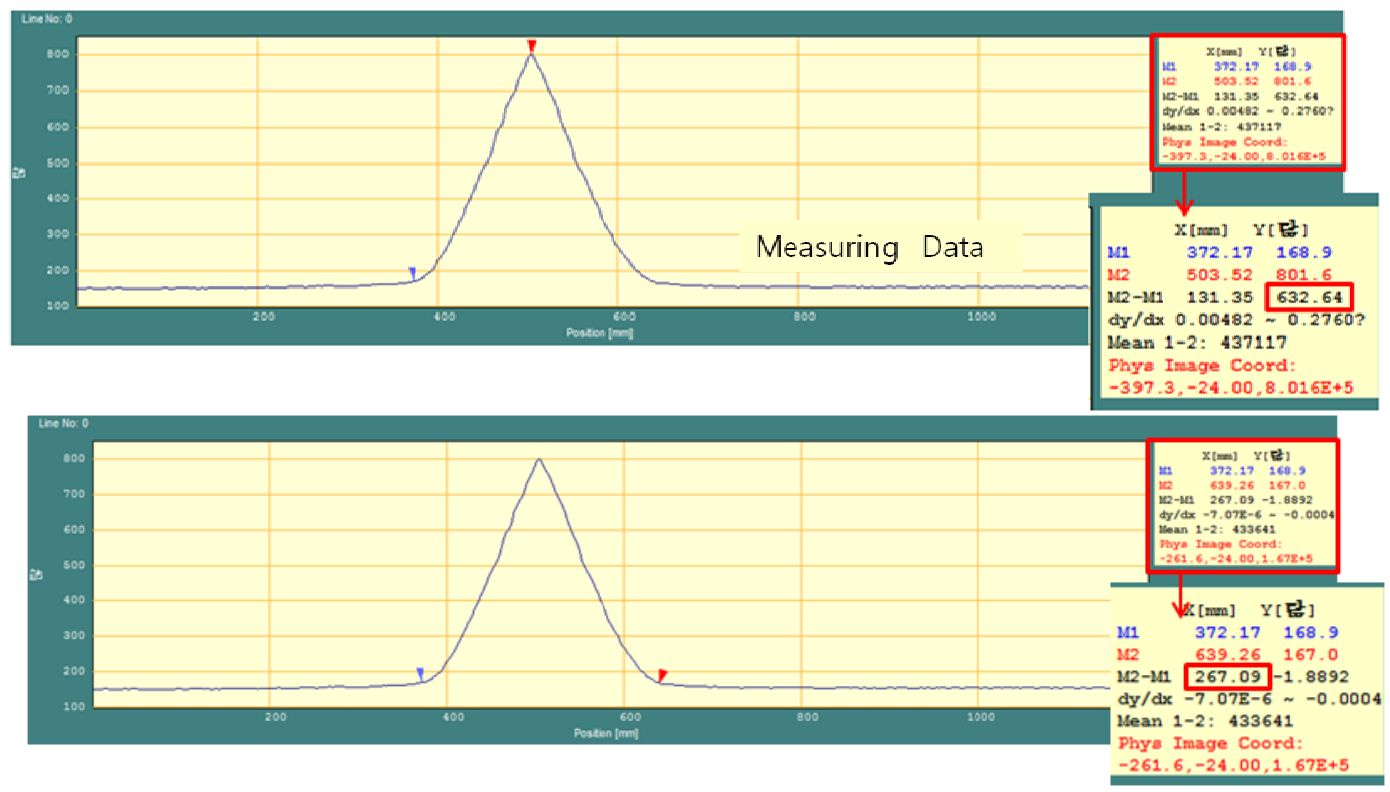

Fig. 16. Measuring sample with height of $800 \mu \mathrm{m}$ and inclined angle of $80^{\circ}$ - existing chromatic confocal

It was expected that the high aspect ratio sample could not be measured as NA of the chromatic confocal was small but the height data were obtained. However, accurate height was not measured with difference of $772.7 \mu \mathrm{m}$ of reference sample and $632.6 \mu \mathrm{m}$. The width was $267.1 \mu \mathrm{m}$ as the same with the reference sample. Therefore, the sample width from the existing chromatic confocal was used while the height data from the chromatic confocal for high aspect ratio was applied for correction. Fig 17 showed the height data using the chromatic confocal for high aspect ratio. 


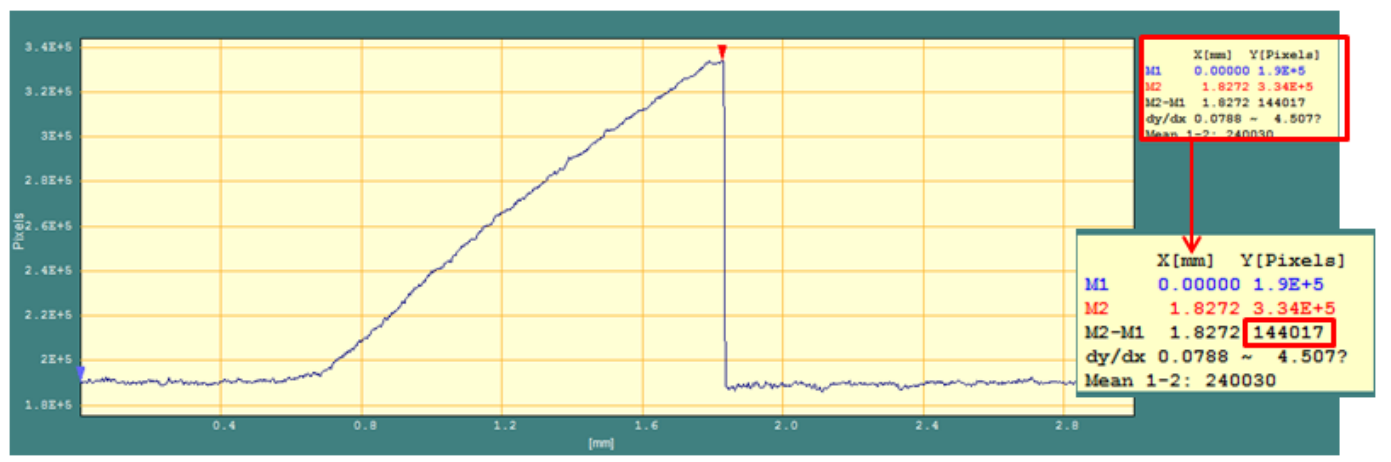

Fig. 17. Measuring sample with height of $800 \mu \mathrm{m}$ and inclined angle of $80^{\circ}$ - chromatic confocal for high aspect ratio

As a result, the height was found 144 pixels. After the measured pixel value was applied to the scale function and the tilting angle of the chromatic confocal was corrected, the height data were calculated at $786.5 \mu \mathrm{m}$. Adding the data from the two chromatic confocal showed the sample width of $267.1 \mu \mathrm{m}$, height of $786.5 \mu \mathrm{m}$ and tilting angle of $80.36^{\circ}$.

The sample with height of $500 \mu \mathrm{m}$ and inclined angle of $80^{\circ}$ was measured with the existing chromatic confocal and the profile was presented at Fig 18.

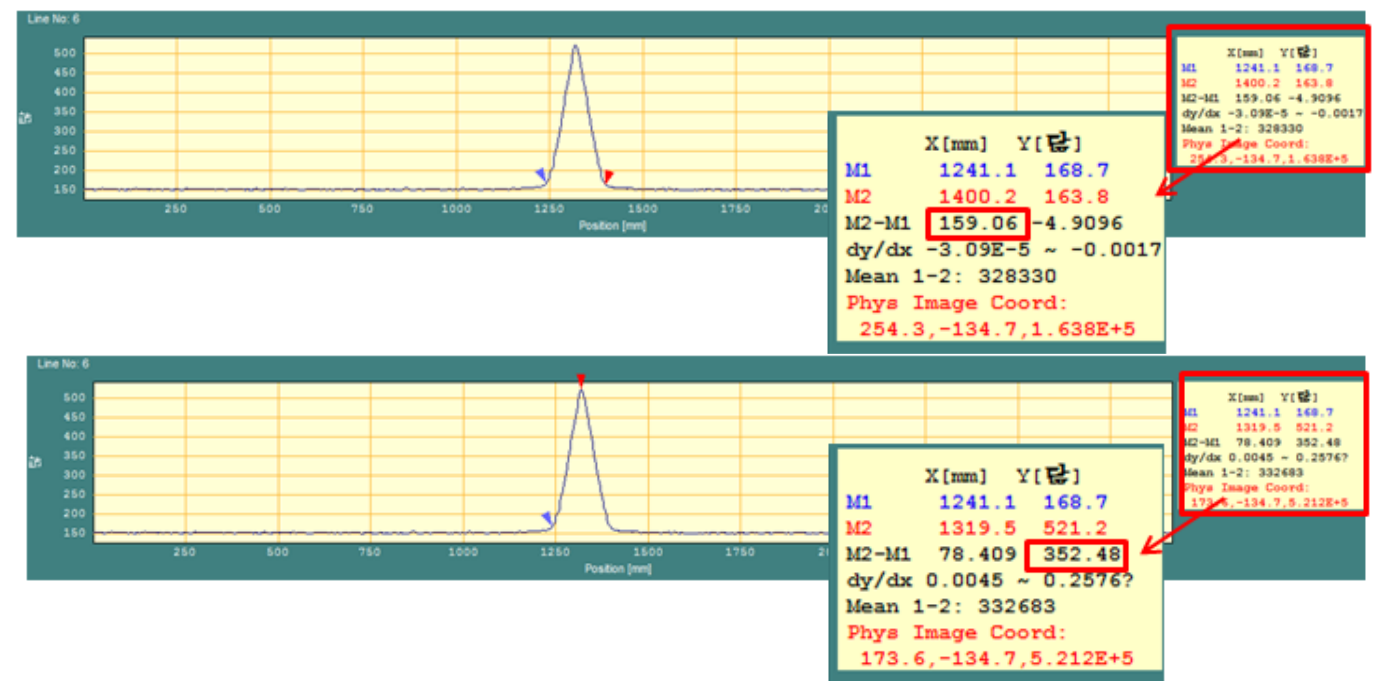

Fig. 18. Measuring sample with height of $800 \mu \mathrm{m}$ and inclined angle of $80^{\circ}$ - chromatic confocal for high aspect ratio

While the reference sample was $452.9 \mu \mathrm{m}, 352.5 \mu \mathrm{m}$ came out, resulting in inaccurate height value. The measured sample width was $159.1 \mu \mathrm{m}$ and the reference sample had width of $157.3 \mu \mathrm{m}$, showing close value. Fig 19 showed the height data measured with the chromatic confocal for high aspect ratio.

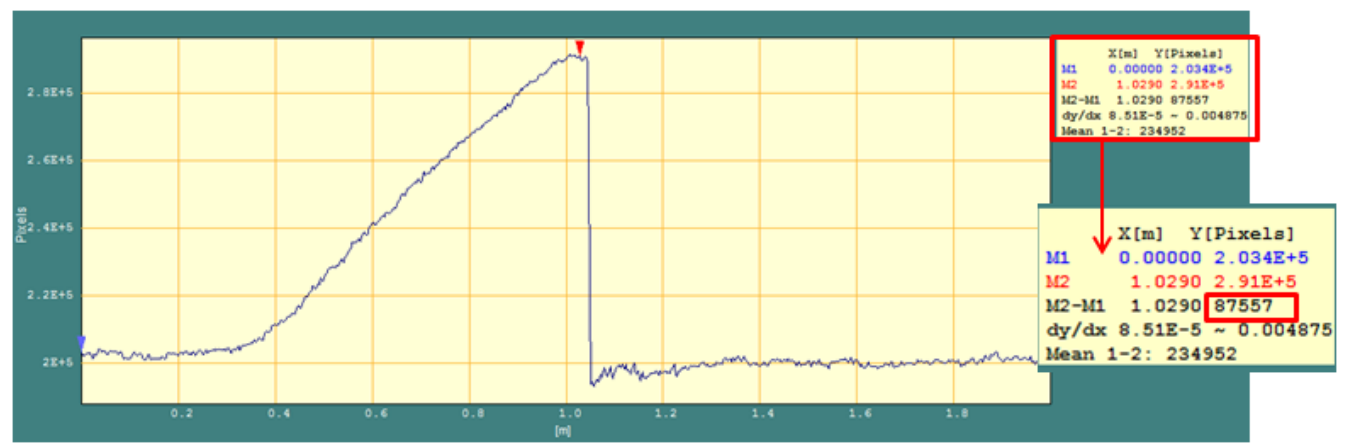

Fig. 19. Measuring sample with height of $500 \mu \mathrm{m}$ and tilting angle of $80^{\circ}$ - chromatic confocal for high aspect ratio

As a result, the height was found 87 pixels. After 87 pixels value was applied to the scale function and the tilting angle of the chromatic confocal was corrected, the height data were calculated $452.1 \mu \mathrm{m}$. Adding the data from the two chromatic confocal showed the sample width of $159.1 \mu \mathrm{m}$, height of $452.1 \mu \mathrm{m}$ and inclined angle of $80.02^{\circ}$. The measured result of the reference sample was listed at Table 3 . 
Table 3. Measurement result

\begin{tabular}{|c|c|c|c|c|}
\hline Sample & Measured item & Reference sample & Result & Error \\
\hline \multirow{3}{*}{$\begin{array}{l}\text { height: } 500 \mu \mathrm{m} \\
\text { tilting angle: } 80^{\circ}\end{array}$} & height $[\mu \mathrm{m}]$ & 452.9 & 452.1 & 0.8 \\
\hline & width $[\mu \mathrm{m}]$ & 157.3 & 159.1 & -1.8 \\
\hline & angle $\left[^{\circ}\right]$ & 80.14 & 80.02 & 0.12 \\
\hline \multirow{3}{*}{$\begin{array}{l}\text { height: } 800 \mu \mathrm{m} \\
\text { tilting angle: } 80^{\circ}\end{array}$} & height $[\mu \mathrm{m}]$ & 772.7 & 786.5 & -13.8 \\
\hline & width $[\mu \mathrm{m}]$ & 267.1 & 267.1 & 0 \\
\hline & angle $\left[^{\circ}\right]$ & 80.19 & 80.36 & -0.17 \\
\hline
\end{tabular}

It was found from the measurement that the angle of high aspect ratio sample had error of about $0.1^{\circ}$. The sample width measured with the existing chromatic confocal did not produce great error. However, the height data measured with the chromatic confocal for high aspect ratio showed error of $13.8 \mu \mathrm{m}$. It was believed that this was attributed to the approximation process of the scale function that calibrated pixel data of Line CCD into height data.

\section{CONCLUSION}

The study suggested the multi probe measurement system for 3D measurement range of a specific measurement subject by integrating the chromatic confocal that could measure structures with large area, high precision and high aspect ratio in the 3D measurement area. It developed two types of chromatic confocal for high aspect ratio in consideration of little light reflection and loss in the optical fiber. The study could reduce loss in the optical fiber in spite of low reflexibility by using the beam splitter that differentiated optical fiber for light incidence and optical fiber for detecting light reflection. Development of the chromatic confocal for high aspect ratio allowed real time measurement of the sample without surface treatment.

\section{ACKNOWLEDGMENT}

This Research was supported by the Tongmyong University Research Grants 2016 (2016F201).

\section{REFERENCES}

[1] Dong-Hyeon Lee \& Nahm-Gyoo Cho, Assessment of surface profile data acquired by stylus profilometer, Measurement science and technology Vol.23 No.10, 2012

[2] Yeon Taek OH, Development of high speed/high precision multi probe measurement system for 3D image measurement, Journal of Korea Soc. Of mechanical technology, 16(6), 2014, pp2097 2103

[3] Chih-Kung Lee and Shui-Shong Lu, "Micro-system displacement and profile measurement by an integrated photon tunneling and confocal microscope," The Chinese journal of mechanics-series A, Vol.18, No.4, 2002

[4] 3. Takashi KODAMA, Hiroyuki OHTANI, Hideo ARAKAWA and Atsushi IKAI, : Development of confocal laser scanning microscope/atomic force microscope system for force curve measurement", Japanese journal of applied physics, Vol. 43, No. 7B, 2004

[5] 4. Jung Hyun Kim, "Surface roughness measurement of bearing balls using Optical Microscope with Vision Sensor", Jou. of Korean Soc. of Mechanical Technology, Vol. 15(2) pp.149 153, 2013

[6] 5. J. H. Kim, "Design of Piezo driven Motion stage using novel cross hinge structure", Jou. of Korean Soc. of Mechanical Technology, Vol. 14(1) pp.1 5, 2012

[7] Yeon Taek OH, "Study of High Aspect Ratio Measurement Using Chromatic Confocal", 2015 International Conference on Informatics, Control and Automation(ICA2015), Phuket, Thailand 